\title{
O novo papel da literatura, a técnica e a relação de ensino e aprendizagem
}

The new role of literature, the technique and the relationship between teaching and
learning

El nuevo papel de la literatura, la técnica y la relación entre ensenãnza y aprendizaje

Nivaldo Medeiros Diogenes ${ }^{1}$

\begin{abstract}
Resumo
Tendo em vista os novos modelos de educação, centrados no uso das tecnologias, este trabalho, fruto de pesquisa de pós-doutoramento, busca compreender a relação entre a literatura e os jogos eletrônicos enquanto estratégia de ensino-aprendizagem. Nessa perspectiva, elenca como objeto de pesquisa o livro-game "Memórias de um sargento de milícias", de Manuel Antônio de Almeida, assumindo como objetivos analisar as possibilidades de recriação literária a partir da tradução intersemiótica entre o livro e o game e discutir a relevância das novas tecnologias para o incentivo à leitura e à produção de textos por parte dos alunos, tanto quanto seu potencial como estratégia pedagógica a ser utilizada pelo professor. Fundamentam essa discussão Johan Huizinga, no que tange ao conceito de jogo, Pierre Lévy, na interação homem-tecnologia e Sônia Rodrigues, na linguagem RPG. Espera-se, desse modo, contribuir para com o processo contínuo de aprimoramento do ensino e aprendizagem.
\end{abstract}

Palavras-chave: Ensino, Literatura, RPG, Tradução intersemiótica.

\begin{abstract}
In view of the new models of education, centered on the use of technologies, this work, the result of post-doctoral research, seeks to understand the relationship between literature and electronic games as a teaching-learning strategy. In this perspective, the book-game "Memories of a militia sergeant", by Manuel Antônio de Almeida, is listed as an object of research, assuming the objectives of analyzing the possibilities of literary recreation from the intersemiotic translation between the book and the game and discussing the relevance of new technologies for encouraging students to read and produce texts, as much as their potential as a pedagogical strategy to be used by the teacher. This discussion is based on Johan Huizinga, about the concept of game, Pierre Lévy, in the man-technology interaction and Sônia Rodrigues, in the RPG language. In this way, it is expected to contribute to the continuous process of improving teaching and learning.
\end{abstract}

Keywords: Teaching, Literature, RPG, Intersemiotic translation.

\section{Resumen}

\footnotetext{
${ }^{1}$ Pós-doutor em letras - Universidade Presbiteriana Mackenzie (UPM); Professor de literatura no colégio Agostiniano Mendel (SAEA) e Secretaria Estadual de Educação do Estado de São Paulo (SEE).E-mail: nivaldomedeirosdiogenes2019@gmail.com ORCID: https://orcid.org/0000-0003-1216-8057.
} 
Ante los nuevos modelos de educación, centrados en el uso de las tecnologías, este trabajo, fruto de una investigación posdoctoral, busca comprender la relación entre la literatura y los juegos electrónicos como estrategia de enseñanza-aprendizaje. En esta perspectiva, el librojuego "Memorias de un sargento de milicia", de Manuel Antônio de Almeida, se cataloga como objeto de investigación, asumiendo los objetivos de analizar las posibilidades de la recreación literaria a partir de la traducción intersemiótica entre el libro y el juego. y discutir la relevancia de las nuevas tecnologías para incentivar a los estudiantes a leer y producir textos, tanto como su potencial como estrategia pedagógica para ser utilizada por el docente. Esta discusión se basa en Johan Huizinga, en lo que respecta al concepto de juego, Pierre Lévy, en la interacción hombre-tecnología y Sônia Rodrigues, en el lenguaje RPG. De esta forma, esperamos contribuir al proceso continuo de mejora de la enseñanza y el aprendizaje.

Palabras clave: Docencia, Literatura, RPG, Traducción intersemiótica.

\section{Introdução}

A recém-situação em que se encontra a cultura favorece o testemunhar de um período rico em incertezas e dúvidas. Até mesmo porque o atual modelo de interação entre os jovens, pautado em mídias de comunicação em que a tela é preponderante, bem como o crescente número de comunidades de adolescentes integradas a um mundo virtual provocam questionamentos frente à relação do sujeito com o conhecimento.

A tecnologia computacional ganha destaque por oferecer-se, para uns, apenas como vórtice de informações duvidosas e espaço rico para a difusão de identidades não confiáveis, ou, ainda pior, para sujeitos cujos propósitos são criminosos, ao passo que, para outros, um novo horizonte de possibilidades e muitas delas ainda desconhecidas dos próprios usuários, os quais, principalmente os professores, atuando no dia-a-dia com crianças, adolescentes e jovens, que, em sua maioria, já nasceram em meio ao uso intuitivo de novas tecnologias.

Os estudiosos em educação chamam a atenção para a necessidade imediata de mudar o formato das aulas e a sua respectiva condução. Entende-se que o aluno contemporâneo percebe o mundo peculiarmente, quando comparado com o de seus professores. Nesse sentido, cabem alguns questionamentos. $\mathrm{O}$ aluno deve se adequar ao professor ou vice-versa? O professor pode impor ao seu aluno a mesma forma de trabalhar conteúdos e/ou competências a que foi submetido? Os novos modelos de educação, centrados no uso de tecnologia, comunidades virtuais, jogos eletrônicos e redes de acesso à informação não devem ser considerados como possibilidades significativas para a escola do século XXI?

Antes de buscar por respostas, considere-se o contexto educacional brasileiro com muitos professores ainda ensinando do mesmo modo que aprenderam. A universidade também tem sua parcela de responsabilidade, ao ofertar uma formação profissional mais voltada para a pesquisa acadêmica e não para o exercício da docência. Ou mesmo instituições 


\section{OO DEVIR EDUCAÇÃO}

ISSN: 2526-849X

que usam as antigas práticas pedagógicas como meio para a obtenção de um reconhecimento na educação. Há quem diga que a prática contínua do ditado seja fundamental para a aprendizagem das palavras ${ }^{2}$.

Até mesmo por uma formação profissional deficitária, muitos docentes interagem com o aluno a partir de uma presença que se afirma pelo medo. Ao passo que, nas comunidades de relacionamento, a oportunidade de seguir alguém que se admira vai ganhando cada vez mais força. Na sala de aula é realmente preponderante ao professor justificar a necessidade de se aprender o conteúdo por meio de uma suposta autoridade que provoca medo no aluno? $\mathrm{O}$ que se ensina hoje realmente faz sentido para o jovem dos novos tempos?

Outro ponto a ser destacado encontra-se na insistente forma de conduzir a prática pedagógica associada a uma extensa quantidade de matérias, divulgadas como fundamentais para o vestibular. A educação para a vida deve ficar relegada a um segundo plano?

Não se pretende estabelecer aqui uma campanha contra os conteúdos escolares, até mesmo porque, sem eles, as competências e as habilidades ficariam inviabilizadas para que o professor atualizado, "antenado", torne visualizável um mundo cada vez mais complexo. Mas é, no mínimo, insólito, com o advento de tantas tecnologias, jogo eletrônicos, ferramentas de comunicação e redes sociais, fazer uso única e exclusivamente de algumas práticas de ensino fundamentadas na cópia de um texto, proposição de questões de entendimento, resolução delas e correção oral, justificando o certo ou o errado tão somente.

A experiência docente nas áreas de literatura e de gramática, mais a inquietação ante a precária condição da educação pública brasileira, são as molas propulsoras para que se tente, ainda que de forma mínima, reinventar o encantamento que a cultura humana pode oferecer aos estudantes. Para tanto, os jogos poderiam despertar o mesmo interesse que os livros já despertaram um dia?

Não parece válida a afirmação que continuamente se ouve de muitos professores: "o aluno de hoje não lê e não escreve". A quantidade de tempo que os adolescentes ficam em frente a uma tela e a quantidade de "conteúdo" gerada nas páginas das redes de relacionamento, Facebook, por exemplo, denotam o contrário. No entanto, é o como se lê que precisa de maior atenção, isso porque o internauta passa rapidamente os olhos sobre os textos, não se demora refletindo sobre eles ou estabelecendo relações entre os links/textos percorridos

\footnotetext{
2 Ver reportagem "Qual é a utilidade do ditado feito pelo professor?", disponível em http://revistaescola.abril.com.br/lingua-portuguesa/fundamentos/qual-utilidade-ditado-feito-peloprofessor-496264.shtml
} 
pelo olhar devorador, tomado de curiosidade crítica. Nesses tempos em que a velocidade impressa no mundo digital cobra praticidade, agilidade, a tela vem substituindo a folha de papel e, com o perdão das empresas de canetas esferográficas e ao professor alfabetizador (tão dedicado ao ensino da letra cursiva), é preciso repensar e, principalmente, recuperar as valiosas conquistas do conhecimento, mais acessíveis agora com o advento da internet.

Portanto, é nesse mar de informação que se pode encontrar relevante quantidade de materiais e ideias merecedoras de atenção da crítica.

Conscientes que pouco se sabe e praticamente nada se utiliza dessa riquíssima fonte de possibilidades encontrada na rede mundial de computadores para o trabalho docente é que se pretende focalizar o game como meio possível para contribuir, ainda que minimamente, na melhoria da educação brasileira.

\section{A literatura e o jogo}

Investigar historicamente sobre o jogo ou sobre a literatura de forma isolada é tarefa plena e satisfatoriamente cumprida por diversos estudiosos. A intenção do presente artigo é levantar alguns dados significativos sobre a recém-aproximação do jogo com a literatura, já que esse movimento pode diametralmente mudar o que estava cravado no campo literário.

Do passado, são diversos os exemplos de jogos originados a partir de clássicos da literatura mundial. Porém, hoje, são os jogos que fornecem o material necessário para a criação de um novo estilo de literatura. Haja vista, o que acontece com a saga Assassins Creed 3 , por exemplo.

Assim como a relação entre o jogo e a literatura gera um novo movimento, tem-se a prática docente exigindo uma contínua reavaliação dos métodos utilizados com os alunos, para que se atinjam os desejáveis e necessários avanços nos índices da qualidade do ensino, em se tratando de Brasil.

Já que a leitura de obras clássicas da literatura e a produção de texto são atividades praticamente desprezadas pelos alunos contemporâneos, a apresentação desses textos em um novo formato pode ser experimentada. É esta experiência de prática docente que se propõe. Paralelamente à demonstração de tal atividade, será apontada a possibilidade de ampliação

\footnotetext{
${ }^{3}$ Antigamente surgia um livro, que gerava um filme para daí surgir um jogo. Hoje, é o caso da saga mencionada, tem-se um jogo que origina um livro e, posteriormente, um filme.
} 
dos significados a partir da leitura de um livro-jogo, uma vez que a transposição midiática é plenamente capaz de sugerir novas relações.

Tem-se de um lado a literatura, expressão tida como difícil pelos alunos, associada em geral às esferas da alta cultura; do outro, o jogo, visto por muitos como uma mera diversão. No entanto, a união das duas linguagens, aparentemente tão distantes entre si, criou laços fortes e, ao longo dos últimos anos, sequestrou a atenção não somente de jovens, mas também de adultos.

É importante lembrar que, segundo Johan Huizinga:

Encontramos o jogo na cultura, como um elemento dado existente antes da própria cultura, acompanhando-a e marcando-a desde as mais distantes origens até a fase de civilização em que agora nos encontramos. Em toda a parte encontramos presente o jogo, como uma qualidade de ação bem determinada e distinta da vida "comum"[...] O objeto de nosso estudo é o jogo como forma específica de atividade, como "forma significante", como função social (HUIZINGA, 2012, p. 6).

O jogo e a cultura, nesse sentido, fazem parte de um mesmo organismo: a sociedade. Além de propiciar uma ambientação distinta, pois o "comum” não está circunscrito em seus domínios, o que já chama a atenção, quando se pensa em uma atividade a conduzir o aluno para vivenciar uma experiência significativa de aprendizagem dentro da escola, tem-se algo quase mágico, pois o jogo pode transportar, cultural e ludicamente, o aluno para fora dos limites do próprio espaço escolar.

Na obra "Homo Ludens: O jogo como elemento da cultura", Johan Huizinga apresenta algumas teorias que definem as origens e a fundamentação do jogo em termos biológicos: como a descarga de uma energia vital, por exemplo, nas brincadeiras que os filhotes de praticamente todos os animais realizam. Já outras apontam o jogo enquanto uma preparação para o jovem que vai enfrentar as tarefas sérias da vida, exercitando-se assim o autocontrole indispensável ao indivíduo. $\mathrm{E}$ as demais pontuam o jogo como um elemento que se liga a alguma coisa que não seja ao próprio jogo, isto é, à premiação.

Opta-se aqui, no entanto, por tomar o jogo como meio para compreender determinados aspectos culturais da vida, e, nesse sentido, ferramenta para proliferar aprendizagem, uma vez que "todo jogo é capaz a qualquer momento, de absorver inteiramente o jogador (HUIZINGA, 2012, p. 11)". Entenda-se, aqui, o jogador também como o aluno, assim o tempo em que ele passa na escola pode ser dilatado pelo prazer no que se está estudando e não cronometrado pelo ócio reflexivo e o tédio. 


\section{OO DEVIR EDUCAÇÃO}

ISSN: 2526-849X

Advertindo a possível ideia de que o jogo possa viciar o aluno, vale destacar que o mesmo só se torna uma obrigação urgente à medida que o prazer por ele provocado necessitar ser mantido por um período ininterrupto. Ou seja, a própria dinâmica da escola, com a distribuição de aulas inviabiliza a perduração do jogo.

\section{Das análises}

O objeto escolhido para o presente estudo é um livro interativo, contendo uma série de onze minijogos, baseados na obra de Manuel Antônio de Almeida, Memórias de um sargento de milícias, que se encontra no site livroegame.com.br/sargentodemilicias/.

Considera-se inicialmente que esse livro-jogo apresenta condições para suscitar no leitor a ação de "percorrer" o espaço que é oferecido, ou seja, não se pode simplesmente olhar para o texto, ir virando as páginas e interpretar o que está escrito. Faz-se necessário coparticipar na construção de uma história que pode ser lida por diversas vezes e sempre trazer novidades. Para tanto, cabe ao leitor interagir com alguns pontos sensíveis na tela, realizar tarefas, ler o texto de outra forma, tentando decifrar esse pequeno mundo que se apresenta.

Portanto, a compreensão do texto é dependente de uma série de fatores: as imagens, a 'jogabilidade ${ }^{4}$, , bem como o texto verbal. Nesse sentido, vê-se o jogo como a manipulação de certas imagens, por meio de lógica indutiva e circunscrita em um tempo diferente ao da escrita do romance. Uma nova realidade então pode ser captada e/ou, pelo menos, observada: as imagens utilizadas na criação do jogo podem completar o que se esvai na leitura mais desatenta.

Ao leitor-jogador cabe a responsabilidade de captar a importância e o significado de cada imagem construída dentro da imaginação do criador do jogo e como ela pode sugerir nova forma de composição de uma narrativa.

\footnotetext{
${ }^{4}$ É um termo na indústria de jogos eletrônicos que inclui todas as experiências do jogador durante a sua interação com os sistemas de um jogo e que descreve a facilidade na qual o jogo pode ser jogado, a quantidade de vezes que ele pode ser completado ou a sua duração.
} 


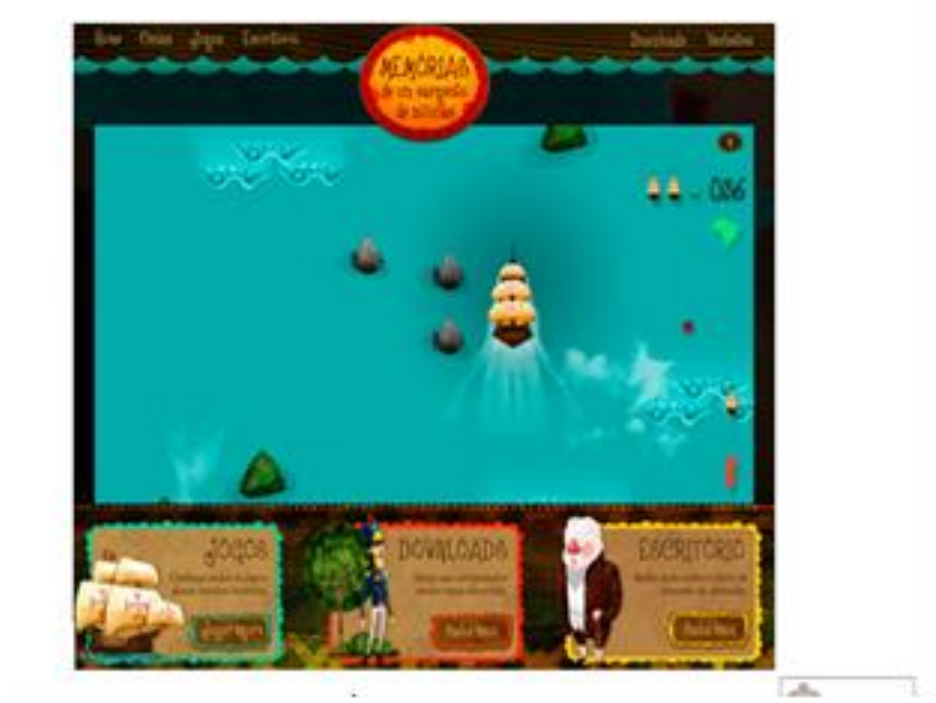

Figura 1 - A primeira tela do jogo

Fonte: http://www.livroegame.com.br/sargentodemilicias/

A rigor, o leitor-jogador vê-se diante de uma imagem em que o tempo em que se desenvolve a narrativa é anunciado no centro superior da tela, com a expressão "Era no tempo de rei...", circunscrita em uma forma oval de coloração muito particular. O tom fortemente alaranjado da borda da figura deixa mais evidente a parte interna da imagem, onde se observa o texto verbal, mas também evidencia uma sugestiva superfície de madeira possivelmente cortada. Nesse sentido, parece estar aí a recuperação imediata do pau-brasil e, evidentemente, toda uma histórica relação entre Brasil e Portugal.

Ainda na mesma tela, o primeiro capítulo é anunciado no canto superior esquerdo "Origem, nascimento e batizado", cuja quantidade de palavras coincide com a de pontos sensíveis ao toque na tela, favorecendo, por sua vez, a aquisição de informações relevantes para a apresentação das personagens.

Cumpre salientar que as palavras visualizadas na cena não apontam obrigatoriamente para um pré-requisito declarado, mas pela própria relação de sentido que a palavra "origem" designa, tem-se, dessa forma, uma orientação sutil. Não obstante, a possibilidade de serem acionadas em ordem aleatória não cancela o entendimento do todo. A isso, vê-se que o livrojogo já foi construído com o propósito de atingir um tipo de leitor mais específico, ou seja, "um leitor ativo, que está a todo momento estabelecendo relações próprias entre diversos caminhos" (LEÃO, 2005, p. 16). 


\section{OO DEVIR EDUCAÇÃO \\ ISSN: 2526-849X}

A obra é construída por meio de uma linguagem hipermidiática e ao leitor-jogador a narrativa se desenvolve quando esse se aventura pela jogabilidade $\mathrm{RPG}^{5}$. Vale ressaltar que tal modalidade se caracteriza justamente pela liberdade que oferece ao jogador, quando disputado no formato representação por personagens, ou quando uma personagem deve atravessar espaços abertos.

Johan Huizinga diz que "a primeira das características fundamentais do jogo, é o fato de ser livre, de ser ele próprio liberdade" (p. 11). Portanto, o livro-jogo estudado aqui traz, em si, uma estrutura rica em novas possibilidades, frente à organização original dado pelo autor do romance, Manuel Antônio de Almeida e, já por isso, relevante.

Não se pretende, contudo, valorizar o jogo em detrimento do livro ou vice-versa. $\mathrm{O}$ que se pode ressaltar positivamente por ora é que o professor de literatura tem mais uma ferramenta nas mãos para promover o prazer pela leitura e o leitor mais uma possibilidade para que se compreenda, por meio da obra literária, o mundo que está à sua volta.

Ainda nos momentos iniciais do jogo, o leitor-jogador se depara com a imagem de uma embarcação, saindo do ponto "Origem" (Portugal), serpenteando ${ }^{6}$ pelo mar até o ponto "Nascimento" e findando o seu percurso, nessa tela, quando chega ao ponto "Batizado", ou seja, nas terras brasileiras. Sobre a caravela visualizam-se três corações pulsando, diferentes em tamanho, o que sugere do maior para o menor, respectivamente, os sentimentos provenientes da relação amorosa entre Leonardo Pataca com Maria das Hortaliças.

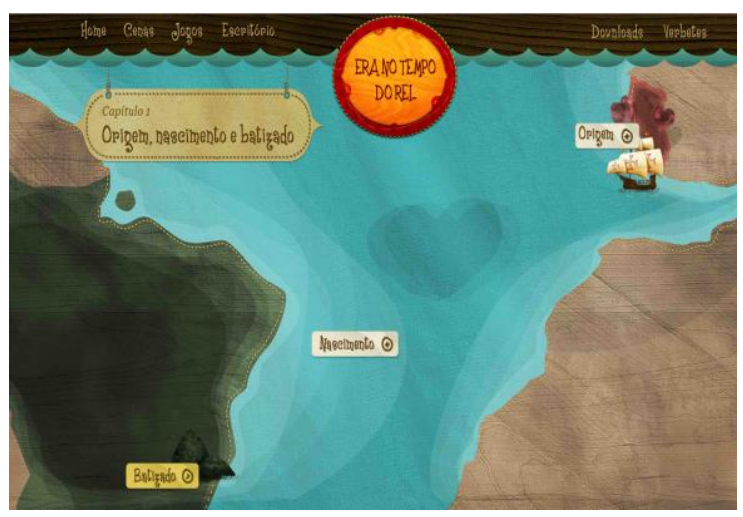

Figura 2 - O capítulo 1

Fonte: http://www.livroegame.com.br/sargentodemilicias/

\footnotetext{
${ }^{5}$ RPG é a sigla inglesa de Role-Playing Game, que em português pode ser traduzido como "jogo de interpretação de personagens". Consiste em um tipo de jogo no qual os jogadores desempenham o papel de um personagem em um cenário fictício, mas também pode ser jogado com o auxílio de um tabuleiro.

${ }^{6} \mathrm{O}$ movimento da embarcação reproduz o jogo de sedução que ocorre em seu interior, ou seja, Leonardo Pataca e Maria das Hortaliças, bem como o próprio ato sexual entre os dois também parece possível de ser entendido.
} 
A dialética das cores utilizadas na cena também é digna de nota, já que Portugal, caracterizado pelo croma vermelho, pode sugerir o simbolismo do princípio da vida (CHEVALIER e GHEERBRANT, 2001, p. 944), ainda que, em se tratando de Brasil, não se pode ignorar uma presença indígena anterior à chegada do branco lusitano. Diante desse quadro, o croma utilizado pode remeter também à ideia da luta, um relacionamento conflituoso, ao menos, para o indígena brasileiro, como atesta a história.

Já o Brasil, em verde, pode ser associado à ideia do desencadear da vida (CHEVALIER e GHEERBRANT, 2001, p. 939). No entanto, a relação entre essas cores é análoga à da essência e à da existência do fogo e da água (CHEVALIER e GHEERBRANT, 2001, p. 938), o que torna possível pensá-las enquanto discurso e, dessa forma, observar um jogo entre a passividade verde-brasileira e a atividade luso-vermelha.

A passividade do lado brasileiro parece ser adensada quando se nota a presença de duas imagens, muito próximas de um uso subliminar, que guardam em seu interior outras possibilidades de significação para o todo. A primeira encontra-se na gradação mais suave entre o verde e o azul, onde a embarcação para, é possível ver um quarto coração, acentuando a ideia do "Nascimento", em correlação com os três corações pulsando sobre a embarcação, dois maiores, um à esquerda e um à direita, e um menor ao centro, este último provavelmente o anúncio do fruto das "pisadelas e beliscões" entre Leonardo Pataca e Maria das Hortaliças. E a segunda, esta formada pelas gradações do azul, frente ao verde do continente brasileiro, sugerindo-se, assim, a silhueta de uma mulher e/ou um ventre com avançados contornos em função da gravidez. De qualquer forma, ainda que fiquem sob suspeita as imagens sugeridas, não há qualquer dúvida quanto à feminilidade dos traços circulares postos em cena para um inicial contexto de caráter sexual.

No plano textual, o primeiro capítulo, "Origem, nascimento e batizado", inaugura o uso de fragmentos da obra original, ou seja, quando o leitor-jogador passa o "mouse" sobre cada ponto tem-se uma sensibilidade imediata e o surgimento da linguagem verbal, mas também se faz uso da não verbal em alguns casos.

Por exemplo, no fragmento textual referente ao ponto "Origem", tem-se, como pode ser visto na figura abaixo, a apresentação das personagens da narrativa, Leonardo Pataca e Maria das Hortaliças. Para tanto, no plano verbal, foram utilizados dois fragmentos (recortes) da obra original e, no não verbal, dá-se ineditamente a criação das respectivas personagens. 


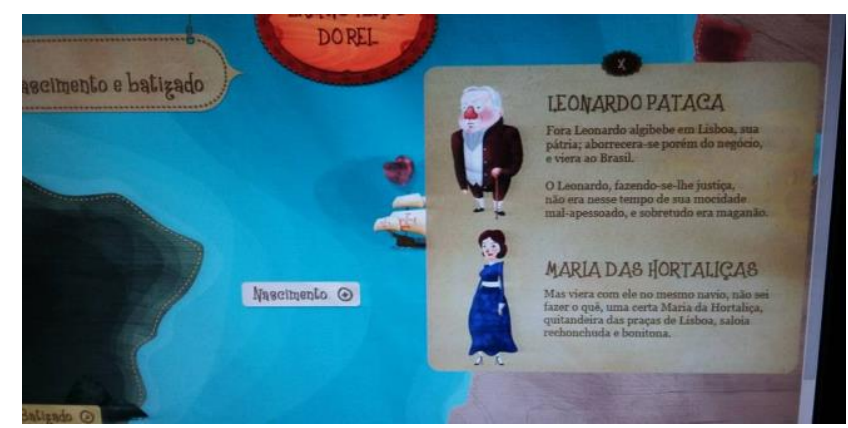

Figura 3 - A apresentação das personagens

Fonte: http://www.livroegame.com.br/sargentodemilicias/

Não é possível determinar o critério utilizado para a construção das personagens, no que diz respeito à linguagem não verbal, até mesmo porque, no caso de Maria das Hortaliças, a referência rechonchuda não parece ter sido levada para a construção imagética da personagem. Isso porque a criação das personagens deve gozar de liberdade na sua constituição plástica, bem como no que tange ao quadro axiológico, motivações e índoles delas. Dessa forma, mais uma rica possibilidade de trabalho em sala de aula com a recriação, por meio de transposição midiática, das personagens de um texto, ou seja, como o aluno o vê.

Ainda na continuidade do primeiro capítulo, mas em uma tela distinta, tem-se disponível aos olhos do leitor cinco quadros distribuídos de forma aparentemente aleatória, uma cadeira, uma janela e uma prateleira, esta última vista somente pela metade, bem como quatro pontos sensíveis ao toque: "A função", "Inspiração para o canto", “Os padrinhos” e "A brincadeira aferventou".

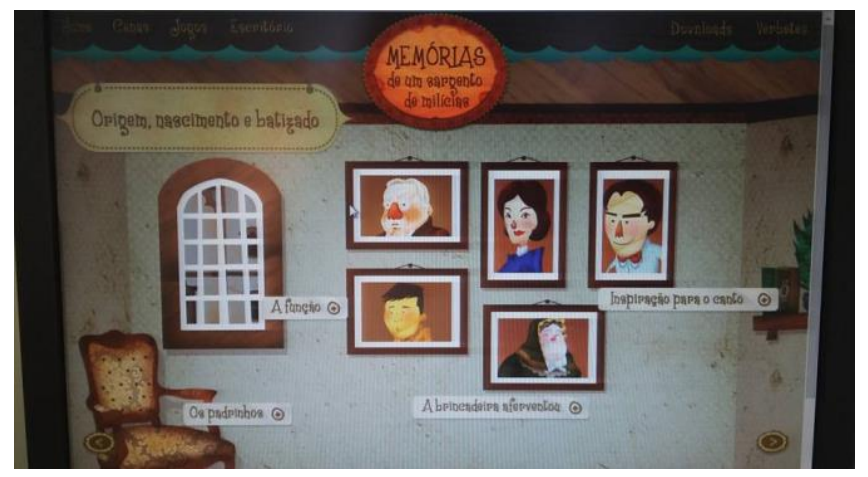

Figura 4 - A apresentação das demais personagens

Fonte: http://www.livroegame.com.br/sargentodemilicias/

Contudo, vale destacar, não há qualquer pré-requisito para que se acione uma tecla hierarquicamente posterior a outra. Posto que o conteúdo de cada elemento não seja dependente de outro item. Mas ao completar-se a leitura de todos os pontos, o leitor é conduzido ao início do segundo capítulo, desde que acionada a seta, no canto inferior da tela.

No segundo capítulo, intitulado "Primeiros infortúnios", chamam à atenção, inicialmente, as rachaduras que aparecem em primeiro plano nas paredes da suposta casa. A 


\section{OO DEVIR EDUCAÇÃO}

ISSN: 2526-849X

isso, deve perceber o leitor-jogador um clima de tensão, que imageticamente se relaciona com a ideia de "Infortúnio".

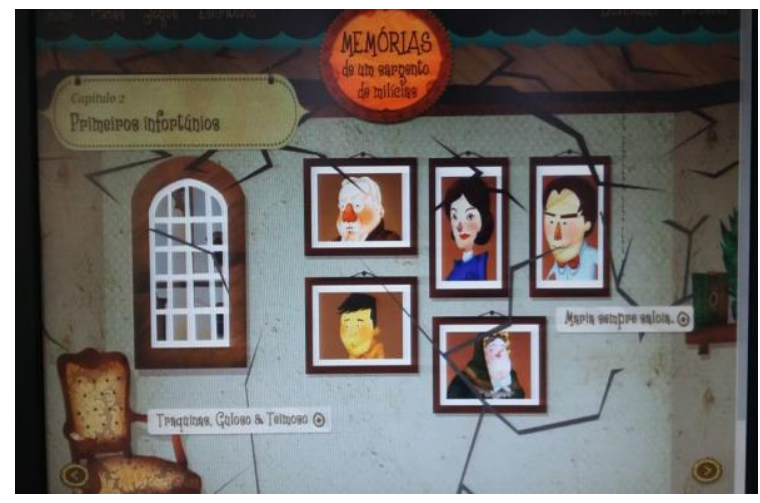

Figura 5 - Primeiros infortúnios

Fonte: http://www.livroegame.com.br/sargentodemilicias/

Na tela, apresentam-se dois pontos sensíveis ao toque: "Traquinas, Guloso e Teimoso" e "Maria sempre saloia...". Não havendo entre eles uma hierarquização. Contudo, vale destacar que as rachaduras das paredes só não atingem a uma imagem dentre os quadros dependurados na parede. O que já é, por si só, uma possibilidade de sugestão para uma única personagem que não terá sua imagem prejudicada.

$\mathrm{Na}$ terceira e última tela do segundo capítulo, mais quatro pontos sensíveis podem ser visualizados pelo jogador e estão disponíveis à interação: “Grandessíssima!”, “Tira-te-lá!”, "Sangue-frio!" e "Filho de piscadela \& beliscão!".

Deve-se atentar primeiramente para o fato de haver uma mesma pontuação para todos os subtítulos (pontos sensíveis ao toque) que compõem a cena, isto é, pontos de exclamação. Nesse sentido, é possível antecipar um período de maior emotividade, em correlação ao emprego de tal recurso. Uma vez ativados os respectivos pontos, de forma automática produzse a queda literal da casa.

Mesmo com o cenário de destruição completo da casa, os quadros, agora caídos ao chão, ainda são visualizáveis, bem como alguns pontos sensíveis: O padrinho, Vá-se tudo com os diabos!, As resoluções de Maria! E com uma carga às costas!. Ainda se devem destacar três imagens acima dos quadros em que o leitor-jogador poderá escolher o seu percurso de leitura.

Diante da necessidade de tomar uma decisão para a escolha de um caminho a ser seguido, o leitor-jogador defronta-se com o que a autora Lúcia Leão chama de "nó", ou seja, "aquilo que faz parar, que nos impede de prosseguir, é o não-lugar que nos suga, a inércia violenta e poderosa. $\mathrm{O}$ nó pode e deve ser utilizado pelos que desenvolvem jogos (games). $\mathrm{O}$ 


\section{OO DEVIR EDUCAÇÃO}

ISSN: 2526-849X

nó seduz aqueles que procuram situações desafiantes, que gostam de decifrar enigmas" (LEÃO, 2005, p. 29).

Assim, para a continuidade da presente análise, optou-se por tomar o primeiro ponto que vai da esquerda para a direita, mas vale lembrar que a tela não sugere nenhuma hierarquia ou pré-requisito.

Em "Quer saber o que aconteceu com a mãe", tem-se a imagem de Maria das Hortaliças destacada no interior de um retângulo em verde, diferente das demais imagens: Leonardo Pataca, em vermelho e Leonardinho, em amarelo. Esta escolha de cores pode evocar um semáforo e ao mesmo tempo sugerir uma espécie de orientação para o trânsito da continuidade de leitura da narrativa.

Seguindo tal raciocínio, fez-se a opção de tocar a superfície em verde, assim feito o leitor-jogador é direcionado à página de um suposto jornal chamado "Correio Mercantil", ano IX, Rio de Janeiro, domingo 5 de junho de $1852, \mathrm{n}^{\circ} 156$, cuja capa traz a manchete "Saudades da Terra”. É importante lembrar que a opção feita para a continuidade do jogo, ou seja, o retângulo verde não traz em si qualquer pressuposto de hierarquização.

Depois de feita a leitura da capa do jornal, o leitor é direcionado automaticamente a uma tela denominada "O que aconteceu com Maria" que, na verdade, é a reprodução de um mar em movimentação no plano de fundo, tendo um barco em primeiro plano, em que a personagem Maria das Hortaliças, de certa forma, virá a ser castigada pelo seu ato de abandonar o filho. Para tanto, são nove as possibilidades de escolha que jogador tem à disposição: a habilitação de uma descarga elétrica proveniente de um relâmpago, dançar até cair no oceano, o ataque de um tubarão, o ataque de gavião, a morte pelo tombamento de um mastro e consequente esmagamento, o afundamento da embarcação, como acontecido com o Titanic, uma onda provocando um tsunami, um salto suicida e ativação de um tiro de canhão.

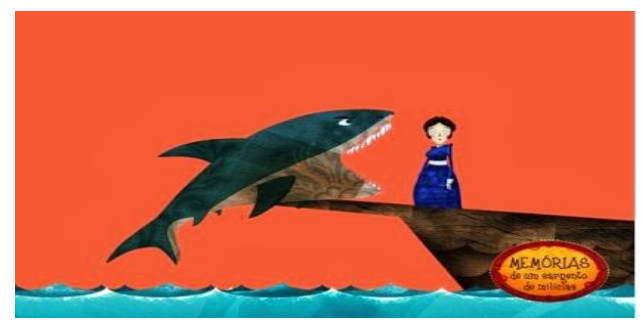

Figura 6 - Um dos castigos para Maria das Hortaliças

Fonte: http://www.livroegame.com.br/sargentodemilicias/

Diante desse quadro, o leitor-jogador, de certa forma, cumpre um papel de juiz e carrasco, sujeitando a personagem Maria das Hortaliças a uma retaliação ante o abandono de seu filho. Embora seja compreensível do ponto de vista da construção do game, tal ação 
merece uma reflexão ante a possibilidade da agressão conferida à mulher. Ainda que o tom dado a muitas das agressões seja caricato, não se pode negar a infelicidade do ato primeiro, ou seja, compensar um erro com a violência ao corpo, principalmente se a vítima for do gênero feminino, o que remonta a todo um passado de luta da mulher frente a esse absurdo que é a violência e o feminicídio. Isso porque, quando

(...) se impõe um castigo a alguém, isto não é para punir o que ele fez, mas para transformá-lo no que ele é. A partir deste momento, atribuir juridicamente uma pena, ou seja, proclamar a alguém "vamos cortar sua cabeça, atirá-lo na prisão, ou mesmo simplesmente aplicar-lhe uma multa porque você fez isto ou aquilo" é um ato que não tem mais nenhuma significação. A partir do momento em que se suprime a ideia de vingança, que outrora era atributo do soberano lesado em sua própria soberania pelo crime, a punição só pode ter significação numa tecnologia de reforma. E os juízes, eles mesmos, sem saber e sem se dar conta, passaram, pouco a pouco, de um veredicto que tinha ainda conotações punitivas, a um veredicto que não podem justificar em seu próprio vocabulário, a não ser a condição de que seja transformador do indivíduo. (FOUCAULT, 2000, p. 138)

$\mathrm{Na}$ continuidade da narrativa-jogo, tem-se uma tela com duas possibilidades "Quer saber o que aconteceu com o pai" e "Quer saber o que aconteceu com o filho", distintas em relação às cores. Optou-se pela segunda, destacada pelo croma vermelho, em que o leitor é direcionado a uma nova capa de jornal. Cumpre lembrar que a escolha feita não é determinada por qualquer hierarquização, ou seja, o leitor-jogador tem plena liberdade na tomada de sua decisão por qual caminho seguir no labirinto da narrativa.

No "Correio Mercantil”, IX, Rio de Janeiro, domingo 5 de junho de 1852, n 156, temse quatro títulos que reconstroem a função de chamadas típicas de um jornal: "O caboclo velho!", "Um novo amor para Leonardo Pataca", "Leonardo e o Nigromante!" e "E uma visita inesperada!". As duas primeiras são demarcadas por meio de cores distintas, sendo "O caboclo velho" em laranja e "Um novo amor para Leonardo Pataca" em verde, já as demais chamadas estão em uma tradicional cor negra.

Optando-se pelo toque na cor laranja, surge um fragmento textual, "O caboclo velho". Ao ser acionada a zona de cor verde outro fragmento textual surge para o leitor, assim como ocorre com as demais superfícies sensíveis ao toque, contudo ao final da leitura dos fragmentos, o leitor-jogador é direcionado para um minigame de cartas, cujo objetivo consiste em vencer personagens por meio de pontuações previamente estabelecidas, a partir de características delas. As cartas foram pensadas em função de determinadas particularidades: coragem, honestidade, riqueza e poder. Portanto, o jogo se dá pela atribuição de pontuações a cada personagem, o que de certa forma ativa no leitor-jogador uma impressão quantitativa 


\section{OO DEVIR EDUCAÇÃO}

ISSN: 2526-849X

sobre o poder de cada um. Numa exemplificação, com a personagem "Primo", cuja riqueza é de apenas 2.5, tem o jogador a possibilidade de utilizá-lo ainda assim no que tange à honestidade que é 8, uma vez que o leitor-jogador escolhe o item a ser utilizado como critério para vencer o adversário.

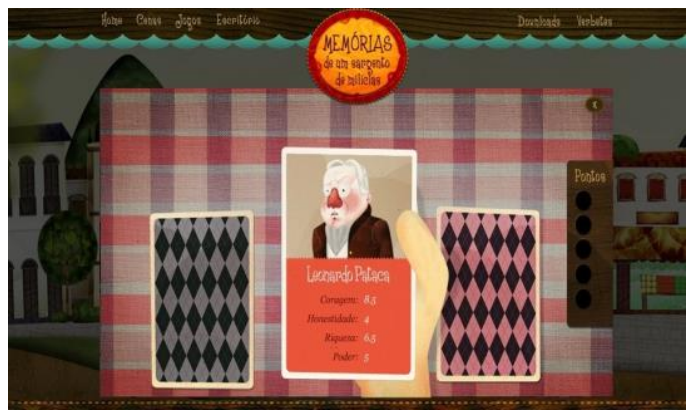

Figura 7 - Jogo de cartas

Fonte: http://www.livroegame.com.br/sargentodemilicias/

É importante refletir sobre outro aspecto do "nó". Além de funcionar como desafio, do ponto de vista composicional/estrutural ele atua como retardamento da narrativa. Este recurso cria o efeito de suspense, alimenta o desejo de o jogador ultrapassar o minigame de cartas para saber o que sucedeu com a personagem. Observa-se, aqui, que essa técnica do game lembra outra existente na ficção literária, ou seja, a presença da ruptura da narrativa com a intromissão de uma digressão e assim ativar o suspense.

Com o minigame findado, resta descobrir o que aconteceu com o pai, ou seja, Leonardo Pataca. Para tanto, o leitor-jogador é novamente direcionado para uma tela no formato de página de jornal, em que algumas matérias estão à disposição de um toque: "Um belo futuro! Será o mesmo?", "E a 'fera' chega à escola!” e "Cuidado, fera solta!”. No caso, optou-se por iniciar o novo percurso que se apresenta pelo primeiro tópico: "Um belo futuro! Será o mesmo?”, contudo cabe lembrar que não há qualquer indício de hierarquia na escolha.

Na continuidade optou-se por acionar o ponto "E a 'fera' chega à escola!" e um novo minigame surge diante do leitor-jogador. Neste é necessário que se desvie a suposta mão de uma criança da palmatória. Para tanto, o jogador pode escolher quatro setas, que ao serem acionadas apresentam a mão de um garoto, constituindo assim o nome do capítulo "A entrada para a escola", mas em que se deve fugir da palmatória para conquistar êxito na proposta.

Com o minigame concluído, inicia-se o subcapítulo "Mudança de vida!”, em que aparece uma vez mais a primeira página do jornal "O Correio Mercantil”, trazendo as seguintes chamadas: "A bossa da desenvoltura!", "Prazer em desobedecer", "Dois bagunceiros incomodam muito mais" e "Um sonho de aventuras!". Ao término da leitura dos 


\section{OO DEVIR EDUCAÇÃO}

ISSN: 2526-849X

fragmentos textuais, surge mais uma nova tarefa a ser cumprida pelo leitor-jogador, isto é, a tarefa de apagar as velas, desde que se faça a sequência correta.

Findado esse percurso tem-se o subtítulo "Amores", em que surge mais uma vez a capa do jornal Correio Mercantil, com as chamadas: "Chega de travessuras!", "O completo vadio!”, “O nome do filho!”, “A sobrinha de dona Maria”, "Quem ri demais...” e "Leonardo para de rir!". Ao fim da leitura dos fragmentos surge um novo minigame em que o leitorjogador deve controlar Leonardo passando pelas paredes que o separam de Luisinha e, assim, vencer o duelo contra Manuel, utilizando a barra de espaço do teclado quando chegar próximo à parede.

Já no episódio "Contrariedades", ressurge a capa do jornal, bem como as chamadas também. São elas “O rapaz amava...”, "Esse tal de José Manoel”, "Leonardo furioso", "Triunfo completo de Jose Manoel", "Remédio para os males". Ao serem totalmente lidos os fragmentos, tem o leitor-jogador diante de si o surgimento de outro minigame, ou seja, um jogo de cartas em que se é necessário escolher a carta de maior numeração e, dessa forma, vencer o oponente. Com a sua resolução e, consequente, vitória do jogador, surge uma imagem em que Leonardo se vê apaixonado por uma personagem - Vidinha.

E em "Novos Amores", uma vez mais se tem a capa do jornal utilizada com as seguintes manchetes: “Amigo é para essas horas!"; "Vidinha! Ah! Vidinha!" e "Seu primo incomoda muita gente". A essa altura da narrativa, o minigame utilizado retrata uma luta entre Leonardo e o primo de Vidinha, que é feita com a ajuda das setas do teclado.

Com a vitória do leitor-jogador frente ao minigame, chega-se ao capítulo " $\mathrm{O}$ agregado", cujas manchetes estão dispostas da seguinte forma: "Declarado agregado"; "Garota movediça"; "Guerra a Leonardo" e "Mais lenha na fogueira". Ao finalizar a leitura de cada item surge ao leitor-jogador um minigame em que é necessário, ao utilizar as teclas com as setas, fugir da janela de Vidinha, uma vez que da mesma são atirados dois sapatos femininos e uma mala.

Com o minigame vencido, chega-se ao episódio “... E, afinal com quem fica Leonardo", cujas manchetes, expostas na capa no jornal, são respectivamente "Notícia inesperada", "A morte é o juiz", "Ideias de comadres" e "Conclusão feliz". Dessa forma, ao serem lidas, há um último minigame que deve conduzir Leonardo a uma fuga. Para tanto, em três minutos o leitor-jogador deve, por meio das teclas direcionais, realizar diversos saltos com a personagem o que acarreta no distanciamento daquele que está em seu encalço, ou seja, chega-se ao final/vitória da narrativa.

Revista Devir Educação, Lavras, vol.5, n.1, p.43-62, jan-jun/ 2021 


\section{A linguagem RPG}

Primeiramente, faz-se necessário entender o sentido do termo RPG, utilizado constantemente como denominação para um tipo específico de jogo. A sigla RPG é oriunda da língua inglesa e significa Role Playing Game. Não há uma tradução oficial, mas de forma livre muitos a fazem como "Jogo de Interpretação de Papéis".

A sua jogabilidade se dá por meio da criação de personagens que participarão da história, a partir da inventividade, do gosto e do gênero de narrativa desenvolvida pelos próprios jogadores. O jogador deve encarnar a personagem criada, deixando a sua vida real de lado e assumindo um novo ser com vida independente, enquanto perdurar a partida.

Nesse sentido, tem-se uma primeira e significativa característica do RPG, ou seja, a de ser um veículo para que o jogador engendre um novo caminho entre o interior de seu mundo e a realidade exterior, ao representar outro ser humano (ou ser com caracterizações e baseado nos humanos) e vivenciar experiências distintas. Para tanto, deve surgir a presença de um mestre ou narrador encarregado de construir os demais elementos da narrativa: cenário, demais personagens, sentimentos, ações que, por sua vez, não são conhecidas pelos jogadores previamente.

Mediante o comportamento de cada jogador, o narrador desenvolve a continuidade da narrativa. Para tanto, há um processo de interação entre jogador e narrador, ou seja, vai e volta. Em linhas gerais, a narrativa imaginada pelo narrador do jogo depende das interações dos jogadores, o que gera a necessidade de surgirem contínuas novidades. Mas não se deve entender tal processo como negativa invariante na condução do jogo, uma vez que diante do novo a criatividade também se faz presente ininterruptamente.

O resultado do relacionamento entre as situações criadas pelo narrador e os caminhos escolhidos pelos jogadores é uma história em processo. Daí uma segunda característica a ser apontada: a narrativa não segue uma pré-determinação, ou seja, sempre será diferente em caso de recontagem da história.

Cabe salientar que o RPG não pressupõe a existência de uma acirrada disputada pela vitória de um dos jogadores, mas sim o término de uma narrativa completa que faça sentido. Dessarte, os desafios lançados devem ser superados de forma colaborativa, talvez aí esteja o verdadeiro sentido da aventura RPG, além é claro da superação das dificuldades impostas, o que gera a ludicidade - diversão.

Revista Devir Educação, Lavras, vol.5, n.1, p.43-62, jan-jun/ 2021 
Como nos ensina o teórico Johan Huizinga, o jogo possui algumas características que se aproximam da literatura, mais especificamente a poesia. Tanto o jogo como o texto poético exercem um fascínio sobre o humano. Nesse sentido, o ato de um novo cosmos com a utilização da linguagem RPG, pode conduzir a aula a uma nova recepção por parte dos alunos e, também do professor, ao menos àquele que se sentir desafiado.

Vê-se então a possibilidade de aproximar o universo do jogo RPG com as aulas do ensino superior, médio ou fundamental. Para tanto, deve o professor utilizar alguma técnica. Portanto, será dado aqui um passo a passo de uma possível aula.

Primeiramente, deve-se sugerir ao aluno que ele pegue uma folha de papel sulfite, ou se não houver a disponibilidade dela, uma folha de caderno é também possível, mas não tão recomendável, por impedir uma melhor visualização dos desenhos.

Em seguida, no passo dois, pode-se começar desenhando um cenário em que a sequência do jogo será desenvolvida e as personagens que farão parte da trama. Ou mesmo uma arena de batalha, se a construção da lógica do jogo prever uma disputa por algo ou alguém.

No passo terceiro, é necessário que se crie a sequência do jogo, ou seja, como a história será desenvolvida, como as personagens deverão atuar, como será o trajeto deles, quais dificuldades a serem enfrentadas, se haverá a disputa por algum elemento mágico ou na ausência de uma ideia mais criativa, pode-se reproduzir os momentos de desenvolvimento de uma narrativa literária tomada como base.

No quarto passo, é hora de preparar as peças que se movimentarão no tabuleiro. A criatividade aqui, nesse instante, pode superar as expectativas. Já que é um outro momento de criação. Se não for o caso, algumas peças, por exemplo, as de um jogo de xadrez, podem oferecer o necessário para a tarefa.

No quinto passo, é preciso determinar alguns últimos detalhes. Por exemplo, em caso de ocorrência de luta entre personagens, em caso de utilização de uma espada, que cause um dado entre dois e quatro pontos no adversário e o do inimigo entre um e dois, a personagem vencedora começa a acumular pontos de experiência de batalha. Assim, ao vencer, a personagem deve ir aumentando uma quantidade determinada para subir de nível. Vale destacar que a personagem deve iniciar a trama com uma quantidade de pontos de vida, ou na linguagem RPG, normalmente se vê a sigla HP. 
Em suma, vai da criatividade do professor e a dos alunos escolherem a modalidade que querem desenvolver, mas independente disso, a linguagem RPG é uma fonte inesgotável para se trabalhar na educação.

\section{Considerações finais}

Do exposto apresentado, parece possível extrair uma possibilidade para reflexão do trabalho pedagógico. Continuamente acusado, o professor de não utilizar estratégias que tornem a aula mais atrativa, parece residir no jogo alternativa com potencial condição para se trabalhar desde a apresentação de uma obra artística, como um quadro, um livro de literatura, ou mesmo oferecer ao professor a possibilidade de intervenção pedagógica para que a aula seja significativa e o principal, oferecer ao aluno mais uma via para compreender por meio dos textos o mundo de que faz parte.

Para tanto, se faz necessária a mediação do professor na introdução do $\mathrm{RPG}^{7}$, desde que a ação esteja fundamentada no conteúdo específico proposto como tema para o desenvolvimento da aventura, ou seja, o planejamento. Dessa forma, os estudantes podem discutir o tema, bem como pesquisar sobre ele para, a partir daí, construírem as personagens e o tabuleiro, caso seja utilizado tal jogabilidade.

Ao utilizar essa metodologia, deve-se lembrar da necessidade de adaptações para o espaço escolar como, por exemplo, a dinâmica dos alunos na sala de aula, as interações com a tecnologia, o diálogo e, principalmente, o surgimento de dúvidas para aqueles que não conhecem as regras de tal modalidade de game.

Parece possível com o que foi levantado até o momento pela pesquisa, resgatar a participação efetiva do professor no processo de aprendizagem, mesmo porque se aprende enquanto se ensina. Além de todos esses ingredientes, de alguns anos para cá, outras vias tecnológicas devem ser observadas com um olhar pedagógico. Não se pode negar a presença de tantas mudanças que atingem diretamente os jovens, e, diante desse contexto, não se pode aceitar que o professor permaneça estagnado. Haja vista, a lembrança de um certo

\footnotetext{
${ }^{7}$ A sigla RPG, oriunda da expressão em inglês "Role Playing Game", define um estilo de jogo em que as pessoas interpretam suas personagens, criando narrativas, histórias e um enredo guiado por uma delas, que geralmente leva o nome de mestre do jogo.
} 


\section{OO DEVIR EDUCAÇÃO}

ISSN: 2526-849X

Maximiliano Máximo Afonso, professor de história ${ }^{8}$, que se tornou ator, pelo menos nos dizeres de José Saramago.

\section{Referências}

ALMEIDA, Manuel Antônio de. Memórias de um sargento de milícias. São Paulo: Martin Claret, 2006.

DOMINGUES, Diana (Org.). A arte no século XXI: a humanização das tecnologias. São Paulo: UNESP, 1997.

FREIRE, Paulo. Pedagogia do oprimido. 50. ed. Rio de Janeiro: Paz e Terra, 2011.

HUIZINGA, Johan. Homo ludens: o jogo como elemento da cultura. 7. ed. São Paulo: Perspectiva, 2012.

LEÃO, Lúcia. O labirinto da hipermídia: arquitetura e navegação no ciberespaço. São Paulo: Iluminuras, 1992.

LEVY, Pierre. As tecnologias da inteligência. Trad. Carlos Irineu da Costa. São Paulo: Editora 34, 1999.

. Cibercultura. Trad. Carlos Irineu da Costa. São Paulo: Editora 34, 1999.

O que é virtual. São Paulo: Editora 34, 1996.

LIBÂNEO, José Carlos. Adeus professor, adeus professora? Novas exigências educacionais e profissão docente. 5. ed. São Paulo: Cortez, 2001.

MACHADO, Arlindo. Máquina e imaginário: o desafio das poéticas tecnológicas. São Paulo: Edusp, 1996.

MANGUEL, Alberto. Uma história de leitura. Trad. Pedro Maia Soares. São Paulo: Companhia das Letras, 2006.

Lendo imagens: uma história de amor e ódio. Trad. Rubens Figueiredo et al. São Paulo: Companhia das Letras, 2001.

OLINTO, H. K.; SCHOLLHAMMER, K. E. (Orgs.). Literatura e mídia. São Paulo: Loyola, 2002.

PLAZA, Julio. Tradução intersemiótica. Trad. Stella Regina A. A. dos Santos e Plínio Martins Filho. São Paulo: Perspectiva, 2003.

\footnotetext{
${ }^{8} \mathrm{Na}$ obra "O homem duplicado", a personagem principal, professor de história, cansado de sua rotina é surpreendido com um fato novo: alguém que exatamente igual. Após inúmeros eventos, a personagem consegue uma nova oportunidade na vida, assumir outra identidade e, dessa forma, vencer a mesmice.
} 
PLAZA, Julio; TAVARES, Mônica. Os processos criativos com os meios eletrônicos. São Paulo: Hucitec, 1998.

- Arte e Interatividade: autor-obra-recepção. Maio de 2000. Disponível em: http://www.plural.com.br/jplaza/texto01.htm. Acesso em: 10/11/2008. Também em: <http://www.ehu.es/netart/alum0506/Ines_Albuquerque/ARTE\%20E\%INTERATIVIDADE.h $\underline{\text { tm}>}$ Acesso em: 20/03/2011.

SANTAELLA, Lucia; NOTH, Winfried. Imagem: cognição, semiótica, mídia. 2. ed. São Paulo: Iluminuras, 1999.

SANTIAGO, Celso. Memórias de um sargento de milícias: livro-game. Julho de 2013. Disponível em: https://www.facebook.com/Livro-e-Game-415867665137481/> Acesso em 10/07/2015.

Recebido em: 20/12/2020

Aprovado em: 18/03/2021 